\title{
The Study on Job Searching Model of College Graduates from the Perspective of Segmented Labor Markets Theory
}

\author{
Chunyan Wang \\ Jiangsu Vocational Institute of Commerce, Nanjing, 211168, China. \\ wangqiao-1977@163.com
}

Keywords: Market segmentation, college graduates, job search.

\begin{abstract}
The labor market is one of the most important production factor markets. Based on the existence of the household registration system, the nature of the enterprise, applicability of policy and so on, China's labor market presents the significant section or duality. This is reflected in the market of college graduates and causes the contradiction of hard employment and talent shortage. Using job search, college graduates are easy to find the primary market positions by minimum reservation wages. However, because of systems' limits, they are difficult to enter and stay in the secondary market. Because the expected utility EU2 moves in the opposite direction with job search costs C, once search costs are higher, then which makes the employment lower than expected demand, it leads graduates not willing to enter the secondary labor market. The key to solute the contradiction lies in three changes: changing the dual labor market, reforming the education system in colleges and universities and changing the concepts of job search.
\end{abstract}

\section{Market Segmentation and Job Search}

\subsection{Segmented Labor Markets Theory.}

In the studies of western economic theories, the labor market is considered as one of the most important production factor markets. About the research perspectives of the labor market, theory systems are very complex, and the most influential of which are New Classical Labor Market and Segmented Labor Markets Theory.

New Classical Labor Market Theory is based on supply and demand theory of new classical economics, assumes that the labor market is unified, competitive one and salaries and positions of laborer is determined by the change of supply and demand relationship in market. In the labor market, workers make career choices, and get in return according to individuals' interests, skills and abilities. Among them, he numbers and form of jobs depends on technology, while salary from each position is related with social habits and institutional factors. Although individual differences in abilities and skills can bring income difference and then form short-term break up in the labor market, the adjustment of the market can make the differences gradually eliminate back into balance for a period. As development of economic and social change, new classical labor market theory is getting more and more difficult to give reasonable explanations in the face of salary distribution, unemployment, employment discrimination and so many existing problems. Accordingly, Segmented Labor Markets Theory is to develop.

Theory hypothesis of Segmented Labor Markets Theory (SLM) is that Labor Markets Theory is not a fully competitive overall, which has always been segmented by many institutions, social organization structure in the reality and form a series of market segments. In all kinds of market segments, although the differences of individual income have certain correlation with laborer, the most important is because there are different mechanisms in different market, and lead same human capital to produce different return rate. To segmented content and flow, the Segmented Labor Market Theory has main points as follows: Firstly, the labor market is segmented into two parts: the primary market and secondary market; Secondly, the workers in the primary market have working stability, higher wages, and better welfare. Returns in the he primary market are mainly determined by systems and rules of society and company, having a few correlations with individual education, skills, ability and so on. Thirdly, the workers in t the secondary labor market have poor working stability, low 
income, low benefits, and lack of promotion prospects. The workers suffered no returns from their education. Fourthly, Labor mobility between the primary market and secondary market almost hardly happens. From the point of Segmented Labor Markets Theory, the difference between a good job 0 and 0 / bad work (or the discretion of the salary) is not because workers' ability and human capital are different, but the industrial structure, product market, technical conditions, management and control strategy and the Labor market regulation, etc. make them to produce.

\subsection{Segmented Labor Markets in China.}

China is a typical dual economy system, where there is the significant section or duality in household registration system, the nature of the enterprise, and applicability of policy and so on. In the terms of segmented labor markets, the most outstanding performance is dual labor market caused by the enterprise nature and segmentation of urban and rural.

I. The dual labor market caused by segmentation of urban and rural

China implements the binary household registration system of the urban-rural division, where labor markets are correspondingly divided into primary market with urban household registration and secondary market with rural registered permanent residence. The primary market is called human resource market, while secondary market is defined as migrant workers labor market. The laborers in the primary market, as formal employees in organization systems, obtain salary, promotion, welfare in accordance with the organization, and share social security, medical care, housing, their children to school and so on citizen treatment in the city; while the migrant workers in the secondary market are seen as "temporary laborers", unable to obtain equal pay, and as migrant workers, they cannot get basic treatments of citizens.

II. The dual labor market caused by enterprise nature

This kind of labor markets are divided into the primary labor market with civil servants, institutions, state-owned enterprises, especially monopoly e enterprises as the main body, and the secondary labor market with private enterprise as the main body. In the former, there are higher salaries, generous welfare, and the workers obtain promotions mainly on qualifications, while the latter there are obvious difference in material rewards, occupational reputation and career development. Not only there are return differences in both markets, but also hardly flow between them. For reasons, Doe ringer \& Pore use negative Feedback 0 to explain. Two workers with the same quality and human capital, for various reasons, respectively go into the primary market and second market; the worker in the latter can't enter the primary part with time flies because he infected with bad habits, such as be late, leave, often changes and undisciplined, etc. and a lack of on-the-job training.

\subsection{Job Search of College Graduation under Segmented Labor Market.}

Phelps (1970) first put forward the professional search theory, which emphasizes, for laborers, that there is insufficient information in the labor market. Workers get the labor market wage distribution by job search activity; and decide whether to terminate the search by comparing the relations between search costs and obtaining marginal benefits. Because China is in economic and social transition, labor market presents the typical duality; and returns of laborers contrasts obviously in the primary and secondary markets, and there are extremely lack of liquidity opportunity between them. For those college graduates who get employment for the first time, whether have an opportunity to enter the primary market or not basically determines their development channel and level in future career. So in order to search a satisfactory profession, a considerable number of graduates prefer to bear unemployment costs for a certain period. Therefore, job search for college graduates is extremely important. Every year, college graduates face reorientations to choose: "voluntary unemployment" or to "secondary market"." Imbalances of human resources market with "graduation is unemployed" and "talent shortage" is also a characteristics of long-standing phenomenon in China.

\section{Job Search Model of College Graduates Based on Market Segmentation}

\subsection{Segmented Hypotheses of Labor Market.}

From point of view of segmented labor market theory, labor market is not a unified market. This paper propose segmented hypothesis of labor market as follows: 
Hypothesis 1: the labor market can be divided into the primary marketL1 and the secondary market. L2.

Hypothesis 2: in the primary labor marketL1, higher salaries as W1, better working conditions, the total demand for college graduates D1, and total supply of college graduates S1 .

Hypothesis 3: in the secondary labor market L2, lower salaries as W2, poorer working conditions, the total demand for college graduates D2, and total supply of college graduates S2.

\subsection{Hypotheses of Basic Job Search Model.}

At present, the basic job search model often used is static partial equilibrium model put forward in 1986 by Mortensen. The hypotheses of the model are as follows:

Hypothesis 4: The model assumes that job seekers do not know the specific wage for each job, only know all kinds of the cumulative distribution of wages for the F.

Hypothesis 5: For a job with a real wage as W, as long as job seekers can accept and he can get the job.

Hypothesis 6: Arrival rate of appointed jobs as.

Hypothesis 7: The cost of job search as $\mathrm{C}$, income not from work during the job search as $\mathrm{B}$, and therefore the net income of job seekers during the job seek is $(B-C)$.

Hypothesis 8: Personal effort to search as e; Assuming that $\lambda$ can be improved by increase of e and also can promote $\mathrm{C}$ to increase; and thus setting: $\lambda=\lambda(\mathrm{e}), \lambda_{\mathrm{e}}{ }^{\prime}>0, \lambda_{\mathrm{e}}{ }^{\prime}<0, \mathrm{C}=\mathrm{C}(\mathrm{e}), \mathrm{C}=\mathrm{C}(\mathrm{e}), \mathrm{C}_{\mathrm{e}}{ }^{\prime}>$ $0, \mathrm{C}_{\mathrm{e}}{ }^{\prime \prime}>0$.

Based on these, Mortensen put forward the concept of reservation wages, that is the only best salary, making job seekers Cross term utility maximization. When a job salary $\mathrm{W}$ is greater than or equal to the reservation wages, job seeks accept the job; or they reject the work and continue to search. Only when two conditions are established at the same time, job seekers can exit the unemployed, participate in employment. One is to receive employment contract, the other is current employment wage $\mathrm{W}$ is greater than or equal to the reservation wages. Because this article researches ob. search problem of college graduates job search problem, therefore the paper adds a new hypothesis of time interval on these existing basic assumptions.

Hypothesis 9: The period of job search behaviors for college graduates is from six months before graduation six months after graduation.

\subsection{Analyses of Job Search in Main Markets.}

The hypothesis 2 and 5 shows that the primary market has higher wages; and college graduates are able to search for some salary higher than their reservation wages, but because of objective system constraints, college graduates can't get employment smoothly in main markets, unable to enter. That is to say, is higher, turnover rate Q1 0 , but D1 S1, job search cost is higher and arrival rate of employment contract is lower.

If a college graduate finds a job with salary w1 in the primary market, his personal discount rate as $r$, arrival rate of work contract as, and discounted utility after employment is ; the probability of failure to obtain employment, discount utility .

According to the expected utility function, expected employment utility of college graduates is used EU1to express. In the primary labor market, college graduates try their best to seek for maximizing expectation utility, EU1 $>0$.

To simplify to,

$$
\text { Namely EU1= }
$$

In the end,

According to the above analyses, expected employment utility f college graduates EU1. Therefore, in order to increase the expected utility, assuming arrival rate of work contract is fixed, and then college graduates should try to decrease the cost of job search, or improve the non-wage income during job search $\mathrm{B} 1$ or try to search for higher wage.

II.Because cost of job search $\mathrm{C} 1$ and arrival rate of work contract are also functions of search effort e1, using formula 1 to derivative for e1.

If a graduate wants to acquire higher expected utility by increasing search effort e1, and must get 
According to above analyses, if a graduate hopes to increase expected utility EU1 by increasing search effort $\mathrm{e} 1$, he should decrease or increase.

From the above analyses, it shows only when and are all met, college graduates can get employment smoothly.

As a result, in the primary labor market, assuming that the arrival rate of work contract fixed, college graduates should try to decrease search cost $\mathrm{C} 1$, or improve the non-wage income during the job search B1 and or try to search for higher wage W1. If they want to increase expected utility EU1 by increasing search effort e1, they should try their best to or increase.

\subsection{Analyses of Job Search in Secondary Markets.}

By hypothesis 3 and 5, we can know wage W2 in the secondary market is lower, jobs are not stable, turnover q2 is higher, arrival rateof work contract $\lambda_{2}$ and search costs C2 are lower, and D2 $\rightarrow \mathrm{S} 2$.

Although each search of college graduates is independent, the number of work sample in the secondary labor market is infinite; it is assumed wages College graduates face in the secondary labor market are the normal distribution with obedient to $\mu$ as average and $\mathrm{R} 2$ as variance. The probability of wage distribution is F (W2).

Reservation wages is the key factor to determine college graduates keep employment in the secondary market. Assuming reservation wage of one college graduate is $\mathcal{X}$. When a random job, $\mathrm{W} 2 \geq \mathcal{X}$, he accepts the job. If $\mathrm{W} 2 \leq \mathcal{X}$, he will decline to the work and continue to search

According to maximization principle of employment utility, we can deduce the formula of model in the secondary labor market is:

$$
\mathrm{EU} 2=\mathrm{B} 2-\mathrm{C} 2+\frac{\lambda_{2}}{\gamma+q_{2}} \int_{\chi}^{\infty}\left(W_{2}-\chi\right) \mathrm{dB}(\mathrm{W} 2)
$$

Making derivative from formula $2 \frac{\partial E U_{2}}{\partial C_{2}}<0$.

We can say expected utility of college graduate EU2 in the secondary labor market is in opposite direction with job search cost C. Although there are more opportunities in opportunity, due to the expected utility EU2 is in opposite direction with job search cost C, and once there are the search costs, it will make employment is below than expected demand and then lead to college graduates reluctant to enter the secondary labor market.

\section{Market Segmentation and Job Search}

This paper uses the theory of job search to construct modeling and give analyses on employment problems of college graduate under the dual labor market; has carried on the theoretical analysis, and drawing conclusion is as follows:

I. It is the first choice for college graduates' job search to enter the first market with higher returns and they are willing to pay the material, time as search costs. Although by paying more search costs, college graduates can search positions higher than expected reservation wages, because of various institutional constraints, the majority of graduates are hard to get into.

II. In the secondary market, graduates' search cost is inversely proportional with the market expected utility, leading to reluctant to enter into this market.

III. The dual labor market is the fundamental reason of conflict why there are "hard employment" and "talent shortage" in the current employment market of college graduates.

Based on the above analysis, this paper suggests solving problems of college graduates employment will need to complete three changes:

Firstly, changing the dual labor market. We should reduce returns difference between the primary labor market and the secondary labor market by developing the third industry; and gradually realize the integration of human resource market by reforming household registration systems, establishing modern enterprise systems and so on.

Secondly, reforming the education system in colleges and universities. We should deepen reform of education system, improve major setting, curriculum system, teaching mode and targeted employment market demand, and reduce job search cost of college graduates. 
Thirdly, changing the concept of job search. College graduates need to change concepts, realize employment from in the "city" to "grassroots", from "public" institutions to "private" unit and implement from "work" to "entrepreneurship".

\section{Acknowledgements}

This study was supported and sponsored by the Education and Science Fund of the 13th-five project of Jiangsu Province (D/2016/03/69), the Qing Land Project, the Third Jiangsu Overseas Research \&Training Program for University prominent Young \& Middle-aged teachers and Presidents, the Key Project of Jiangsu Vocational Institute of Commerce (NO.JSJM16002), Excellent Innovation Team Fund of Jiangsu University Philosophy and Social Sciences (2017ZSTD028), and Excellence Team Fund about Economic and Technological Innovation of Jiangsu Vocational Institute of Commerce. We are grateful for their supports.

\section{References}

[1]. Zhaoshi Zhang1, Xuan Zhang2. Segmented Labour Market Theory: Theory Background and Evolution. Journal of Chongqing University. Vol. 15(2009) No.6, p.57-62.

[2]. Ping Wang. University Graduate Job Search Behaviour-Based on Labour Economics Perspective Analysis. Journal of financial research. (2010) No.6, p.111-118.

[3]. Yuen Zhang. Selective Unemployment of College Students Attribution Analysis-from the Angle of Dual Segmented Labour Market Theory. Journal of higher engineering education research. (2009) No.3, p.70-73. 